\title{
AUTOCRACIA DE LA RAZÓN, LIBERALISMO DE LOS DERECHOS, DEMOCRACIA DE LOS GARANTES. EL PROGRAMA NORMATIVO DE LUIGI FERRAJOLI *
}

\author{
Pier Paolo Portinaro \\ Universidad de Turín
}

RESUMEN. El trabajo analiza las contradicciones de la propuesta normativa de FERRAJOLI de una democracia garantista, que podrían sintetizarse en el intento de hacer compatible una sociedad idealmente liberal con con una visión del orden público que podría definirse como solidarismo republicano.

Palabras clave: L. FERRAJOLI, garantismo, democracia.

ABSTRACT. The work analyzes the contradictions in FERRAJOLI's normative proposal for a guaranteeing democracy, which could be synthesized in an attempt to make an ideally liberal society compatible with a vision of public order which could be defined as republican solidarity.

Keywords: L. FERRAJOLI, guaranteeing, democracy.

* Fecha de recepción: 1 de diciembre de 2008. Fecha de aceptación: 18 de diciembre de 2008. 


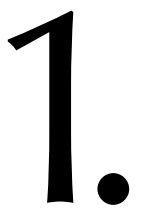

En la reciente literatura filosófico-jurídica y filosófico-política del continente europeo, en el que tras trágicas vicisitudes se ha llevado a su máxima expresión el experimento histórico de la democracia constitucional, hay dos obras que dan la sensación de que aquella época de afortunada conjugación entre Decho y politica se halla próxima a concluir, y ello pese a la virtuosa obsDerecho y de los derechos se propone nuevamente, debidamente potenciado o, mejor dicho, radicalizado, como respuesta irrenunciable a los desafíos del siglo XXI. Faktizität und Geltung. Beiträge zur Diskurstheorie des Rechts und des demokratischen Rechtsstaats de J. Habermas, y Principia iuris. Teoria del diritto e della democrazia de L. FerRAJOLI, pueden ser consideradas, tras un periodo de sobriedad empirista y procedimental, como las obras que en el curso de los últimos diez años en este continente mejor han conciliado, con pasión moral y espíritu sistemático, la teoría del Derecho y la teoría de la democracia; y esto a fin de redefinir un paradigma muy exigente de democracia constitucional (nótese la convergencia de sus pretensiones que claramente expresan los subtítulos) orientado a instar a los Estados nacionales ya en declive a mantener aquellas promesas de democracia y Estado de Derecho que, en una sociedad global cada vez más fragmentada y cada vez más polarizada social y culturalmente, se hallan puestas en riesgo.

Se trata de dos obras aparentemente muy distantes por las tradiciones intelectuales a las cuales pertenecen y por la estructura teórica que las formula. Detrás de HABERMAS está la teoría crítica de la sociedad y la tradición hermenéutica alemana, confrontadas con la filosofía política normativa estadounidense del último decenio; detrás de FERRAJOLI, el normativismo kelseniano filtrado por la teoría política de BOBBIO (en la estela de BOBBIO, FERRAJOLI sigue siendo un pensador con orientaciones cosmopolitas, pero fundamentalmente eurocéntrico; en efecto, si una cosa llama inmediatamente la atención del lector de Principia juris es seguramente la exigüidad del diálogo con la cultura jurídica y política estadounidense, o en general anglosajona). Mientras el primero ha edificado su reconstrucción de la democracia constitucional sobre la teoría de la acción comunicativa, el segundo nos propone una teoría axiomática formal del Derecho y busca extender sus asimilaciones a la teoría de la democracia ${ }^{1}$. No obstante, lo que les acerca es una finalidad crítica radical, dirigida, en el heredero de la escuela de Frankfurt, contra la tradición filosófica dominante del siglo XX (entre NIETZSCHE y HeIDEGGER) y en FERRAJOLI contra la tradición jurídica hegemónica y su supuesta neutralidad política ${ }^{2}$, y dirigida a denunciar el «lado oscuro de Occidente» y el modo en el que se recurre a políticas (económicas y militares) que se muestran en evidente contradicción con sus propios principios ${ }^{3}$.

${ }^{1}$ L. FERRAJOLI, 2007: Principia iuris. Teoria del diritto e della democrazia, Roma-Bari: Laterza, II, p. 6, advierte que no quiere proponer una teoría formal ni formalizada de la democracia sino una «teoría normativa, que hace uso de todo el aparato conceptual elaborado por la teoría formal del Derecho, la cual representa una interpretación semántica del tipo axiológico o normativo, basada no obstante en la experiencia constitucional de las actuales democracias». El fundamento de esta teoría jurídica de la democracia constitucional es, como se muestra en I, $\mathbb{S} 12.18$, la teoría de la validez (formal y substancial) de las normas.

2 Téngase presente lo que L. FerRAJOLI, 1999: La cultura giuridica nell'Italia del Novecento, Roma-Bari: Laterza, p. 7, escribe acerca de la «doble operación de despolitización llevada a cabo por los juristas a partir de la segunda mitad del siglo pasado: de su objeto de investigación, o sea, del Derecho y del Estado, de los cuales éstos teorizan la neutralidad y la neutralidad política, y aún antes del mismo trabajo que desempeñan, o sea de la doctrina jurídica, que éstos configuraron como "ciencia" no valorativa».

${ }^{3}$ L. Ferrajoli, Principia iuris, II, p. 570. Cfr. J. Habermas, 2005: L'Occidente diviso, Roma-Bari: Laterza. 
Por lo que se refiere a la cultura jurídica italiana, es relevante la deuda de esta obra en relación con la aportación de N. BobBio a la teoría general del Derecho ${ }^{4}$. Sin embargo, respecto al programa científico bobbiano de una teoría formal, en cuanto no valorativa, del Derecho, debe señalarse que FERRAJOLI ha denunciado el carácter ilusorio y la sustancial incomprensión de las innovaciones introducidas en la estructura normativa del Derecho por el Estado constitucional de Derecho, oponiéndolo a la tesis del carácter crítico y constructivo de la ciencia jurídica ${ }^{5}$. Si tuviéramos que resumir el aporte teórico de BOBBIO a una fórmula excesivamente simplificada, creo que se podría decir que fue el más kelseniano entre los intérpretes de HOBBEs y el más hobbesiano entre los intérpretes de Kelsen. Hoy en día es indudable que HobBes puede ser considerado el autor de la primera teoría axiomática — si bien no propiamente formaldel Derecho y de la política, así como el primer partidario moderno riguroso del nocognotivismo ético. Del mismo modo, para FERRAJOLI, cuyo concepto de soberanía (II, p. 487) toma distancia debidamente del «realismo elemental del primer contractualismo» y de su «aporía» originaria, HOBBES continúa siendo un autor-clave y no sólo desde el punto de vista metodológico. Pese a ello, respecto a las dos líneas fundamentales de pensamiento que el modelo hobbesiano ha conocido: la lockeana, que lleva a la concepción liberal del orden político, y la rousseauniana, que configura la concepción democrática radical, FERRAJOLI, como buen crítico de los derechos patrimoniales, se sitúa más cercano a la última ${ }^{6}$. Y aquí cabe advertir el alejamiento de FERRAJOLI respecto a BOBBIO en lo que se refiere a la teoría de la democracia, y ello por más que DAHRENDORF haya afirmado — aunque superficialmente - un desplazamiento del liberalismo de BOBBIO hacia el pensamiento rousseauniano ${ }^{7}$.

2. Nuestra lectura de este inconmensurable opus puede partir de descifrar la presencia de un clásico, J.-J. RousSEAU; a partir precisamente de la teoría de las relaciones entre democracia y derechos fundamentales elaborada en Principia iuris, puede reconsiderarse a ROUSSEAU en oposición a la tendencia a la vulgata interpretativa que lo convierte en el sostenedor de aquella democracia de la identidad que no habría tardado en desvelar sus implicaciones totalitarias ${ }^{8}$. El concepto de voluntad general es notoriamente el fulcro enigmático y problemático de su doctrina política. La teoría de la democracia de FERRAJOLI nos ayuda a comprender este concepto aún en aquellas valencias que

${ }^{4}$ L. FerRAJOLI, 2004: «L'itinerario di Norberto Bobbio: dalla teoria generale del diritto alla teoria generale della democrazia», en Teoria politica, 20, n. ${ }^{\circ} 3$, p. 127: «BOBBIO fue al mismo tempo el máximo exponente teórico del Derecho y el máximo exponente filósofo de la política de nuestro país en la segunda mitad del siglo XX: seguramente, es aquel que ha dejado la marca más profunda en la cultura filosófica-jurídica y filosófica-política y aquel que más generaciones de estudiosos, aunque de distintas formaciones, han considerado como un maestro».

${ }^{5}$ Cfr. L. FerRAJOLI, La cultura giuridica, cit., p. 102: «Esta idea bobbiana de la neutralidad valorativa de la ciencia jurídica representa un legado, en mi opinión indefendible, de varias tradiciones, todas fuertemente presentes en los años cincuenta: antes que nada de aquella del neopositivismo lógico de los orígenes (...); de la idea kelseniana de la "pureza" de la teoría del Derecho y de aquella weberiana de la neutralidad valorativa de las ciencias sociales; en fin, del modelo apolítico y técnico del jurista propio de la tradición pandectista, aún dominante en la cultura jurídica del tiempo». En Principia iuris, tanto KELSEN como BOBBIO son reconducidos muchas veces, y no sólo bajo el perfil metodológico, al horizonte del «paleo-positivismo jurídico» (II, p. 37).

${ }^{6}$ Para la originaria formulación de la teoría de los derechos fundamentales, así como para el importante debate que se ha desarrollado, cfr. Diritti fondamentali. Un dibattito teorico, a cura di E. VITALE, 2001: RomaBari: Laterza.

7 R. DAHRENDORF, 2007: Erasmiani. Gli intellettuali alla prova del totalitarismo, Roma-Bari: Laterza, p. 88.

${ }^{8}$ Una vulgata interpretativa no priva de justificaciones y anclajes textuales y a la cual el mismo FERRAJOLI parece adecuarse en más de un pasaje de la obra: Principia iuris, II, pp. 114-18, 165-66 y 546. 
el aparato conceptual del siglo de las luces no consentía a ROUSSEAU explicitar completamente. En la introducción del capítulo décimo tercero, tras haber denunciado la insuficiencia y las cuatro aporías de las concepciones procedimentales de la democracia y haberse librado de la tesis holística y organicista de la voluntad general, FERRAJOLI parte de una redefinición de la soberanía popular, a) como garantía negativa («la soberanía pertenece al pueblo y solamente al pueblo»), b) como suma de derechos fundamentales $^{9}$ (II, p. 11).

A menudo se señala a ROUSSEAU como exponente de una concepción substancial de la democracia o también, con buenas razones, como el autor moderno que ha intentado conciliar concepciones formales y concepciones substanciales de la democracia. También FERRAJOLI se mueve en esta misma dirección: la teoría de la democracia elaborada en el segundo volumen de Principia iuris está enteramente orientada a enlazar la dimensión formal y la dimensión substancial, las normas de procedimiento y las normas que afectan a los contenidos de las deliberaciones colectivas ${ }^{10}$. De este modo, adoptando un movimiento hegeliano (aunque luego, en toda la obra, HEGEL y SCHMITT constituyen sus principales adversarios), FERRAJOLI ve en la «racionalidad iusconstitucionalista» una especie de Aufbebung respecto al momento substancial de la racionalidad iusnaturalista y respecto al momento formal de la racionalidad iuspositivista, en cuanto constitucionalismo rígido, permitiendo la subordinación de la ley a los derechos fundamentales restituye «racionalidad substancial a toda la producción jurídica», y realizando al mismo tiempo la conjunción de la democracia, del Estado de Derecho y del propio positivismo jurídico ${ }^{11}$. Empero, en el fondo, también en el programa del Contrato social se encontraba la maximización de la artificialidad del orden, del gobierno de la ley y de la participación democrática.

Obviamente, el RousSEAU de FERRAJOLI está depurado de toda forma de cognitivismo $^{12}$ y de la idea iusnaturalista de un universalismo ontológico de los derechos hu-

9 Principia iuris, II, p. 10: «Fue el mismo RoussEAU quien afirmó que "la soberanía no puede ser representada, por la misma razón que no puede ser alienada" (...) Esto significa que el principio de la soberanía popular equivale a una garantía negativa». Los derechos equivalen «igualmente a fragmentos de soberanía popular en beneficios de todos y de cada ciudadano. Por eso cada violación suya es una lesión no sólo de las personas que son titulares, sino también de la soberanía popular». Es éste el sentido del famoso art. 34 de la Declaración de los derechos premisa de la Constitución francesa del 24 de junio de 1793: «Existe opresión contra el cuerpo social cuando tan sólo uno de sus miembros es oprimido». En cambio «cualquier concepción de la soberanía como potestas legibus soluta entra en contradicción no sólo con el modelo de la democracia constitucional, sino con la idea misma de la democracia, revelada históricamente y conceptualmente incompatible con la existencia de poderes soberanos o absolutos, comprendida la omnipotencia de la mayoría del pueblo y de sus representantes» (II, pp. 9-11).

${ }^{10}$ Es forma-substancia, evidentemente, la gran dicotomía que está en la base de todas las dicotomías que estructuran su construcción teórica: «Nuestra distinción entre "dimensión formal" y "dimensión substancial" de la democracia recalca una dicotomía que ha atravesado la entera teoría del Derecho desarrollada hasta aquí: aquella entre signo e significado, y luego entre causa y efecto, entre forma y substancia, entre fuentes y normas, entre medios y fines, entre validez formal y validez substancial, entre normas formales y normas substanciales, entre nomodinámica y nomoestática, entre funciones de gobierno y funciones de garantías, entre normas de reconocimiento y de razones sociales de cualquier institución» (II, p. 24).

${ }^{11}$ «La racionalidad iusconstitucionalista (...) une racionalidad formal y racionalidad sustancial, dado que vincula y finaliza la primera a la segunda, a su vez positivizada. Ésta consiste en la congruencia de los medios - el obrar económico en las formas de la autonomía privada y el obrar político en las formas de la autodeterminación política colectiva - con los fines y las expectativas constitucionalmente estipuladas» (II, p. 41).

${ }_{12}$ Una polémica con el cognitivismo de clara matriz kelseniana recorre toda la obra: es decir, la intolerancia «es siempre relativa a cada forma de cognitivismo ético-político» (II, p. 568). 
manos (al menos esto pretende). Y es sobre todo crítico en relación con la noción rousseauniana de voluntad general. «La llamada "voluntad general", no es tanto no representable, como afirmó RousSEAU, cuanto inexistente» (II, p. 172). De la crítica de los conceptos metafísicos de una teoría de la democracia de matriz rousseauniana proviene la crítica de una tradición de constitucionalismo democrático que ve en la nationbuilding y en la integración política de un pueblo, no el efecto sino el presupuesto de la constitución. En relación al debate sobre la posibilidad de una constitución europea, FERRAJOLI niega que no se pueda dar constitución sin pueblo. «Es verdad, al contrario, que no hay pueblo sin constitución» (II, p. 563). Da aquella crítica deriva complementariamente una recuperación de los «clásicos principios liberales según los cuales: a) los hombres, sobre todo si detentan poder, están, o de todos modos es bueno suponer que están, predispuestos a la maldad o inmoralidad; $b$ ) no es absolutamente factible englobar a la humanidad en una "unidad moral", puesto que está dividida por valores, culturas e intereses diversos y antagónicos; $c$ ) los seres humanos, a su vez, son diferentes unos de otros, a causa de condiciones sociales, intereses económicos y concepciones políticas y morales que virtualmente entran en conflicto» (II, p. 569). Como bien sabemos, esta filosofía social y antropología política —correctamente identificadas como liberales - constituyen las antípodas de la filosofía social y de la antropología política de ROUSSEAU. De hecho, es exactamente aquí, creo, donde se puede identificar la paradoja de la filosofía política que presupone toda la construcción de FERRAJOLI: el querer hacer convivir, siguiendo las problemáticas indicaciones kantianas, pero yendo más allá de KANT, una filosofía social idealmente liberal (un liberalismo de los derechos y no de los intereses) con una visión del orden público que podría definirse como solidarismo republicano.

Que el liberalismo de FERRAJOLI no es el liberalismo de la tradición clásica, sino un liberalismo depurado del dificultoso bagaje de las apologías de la esfera (y de la propiedad) privada, lo demuestra puntualmente el tratamiento que su teoría de los derechos fundamentales reserva a los derechos patrimoniales (de propiedad o de crédito), considerados particulares y disponibles y por lo tanto contrapuestos a los derechos fundamentales (de libertad o de autonomía), que en cambio son universales y no disponibles: una distinción que me parece perfectamente integrable (si se considera el espíritu y no la letra) en la construcción teórica de RousSEAu. Aquí, el espíritu del ginebrino renace en la denuncia del despotismo de los poderes privados. La gran laguna de nuestra tradición jurídica consiste, para FERRAJOLI, en el hecho de que no se ha desarrollado «al lado del constitucionalismo de Derecho público, un constitucionalismo de Derecho privado» (II, p. 224). Para un liberal clásico una afirmación de este tipo sólo podría ser insensata: esto es así porque lo que correspondería a la constitución como pacto público en la esfera privada sería el contrato garantizado por el juez; establecer ulteriores límites al ejercicio de poderes privados equivaldría a una recaída en el despotismo. Sin embargo, para un republicano à la ROUSSEAU es seguramente cierto que también los poderes privados amenazan la libertad y la autonomía de los individuos y, por tanto, deben ser sometidos al Derecho ${ }^{13}$.

\footnotetext{
${ }^{13}$ No obstante, manteniéndose en el ámbito de una concepción liberal-democrática, tampoco la crítica a las «falacias ideológicas» tendiente a la concepción de la representatividad (II, pp. 174 y ss.) es extraña a la lección rousseauniana.
} 
En una acepción corriente, genérica o vulgar, la democracia substancial constituye un fortalecimiento de la democracia, una potenciación del poder popular. No es así en FERRAJOLI, y tampoco en una posible interpretación no concretista y no substancialista de la voluntad general de ROUSSEAU. Las reglas de la democracia formal son aquellas «orientadas a disciplinar los medios y las formas de las decisiones, que reservan al poder y a la voluntad de los particulares en la vida privada y a la voluntad de la mayoría en la vida pública, permaneciendo indiferentes a sus fines sin predisponer su sustancia. Por esta razón, estas reglas consisten en la atribución de los derechos secundarios o instrumentales o de autonomía, individual o colectiva, mediante normas formales que condicionan su válido ejercicio a la innovación y transformación jurídica». Sin embargo, las reglas de la democracia substancial consisten para FERRAJOLI «en límites y vínculos a la autodeterminación individual y colectiva, orientados a la tutela de intereses y necesidades vitales de todos. Consisten, por tanto, en la atribución de los derechos primarios o finales o substanciales que disciplinan la autodeterminación en el ejercicio de los poderes, de lo contrario absolutos, en los que consisten los derechos secundarios» (II, p. 17). En virtud de estas determinaciones, que se apoyan sobre la distinción entre «derechos secundarios» $\mathrm{y}$ «derechos primarios», la democracia substancial aparece como un debilitamiento de la democracia, como su constricción en una jaula de vínculos y de límites que disciplina y racionaliza coercitivamente a los intereses particulares. Creo que a un ROUSSEAU redivivus le podría gustar esta solución a la paradoja democrática.

La reinterpretación de la noción de soberanía en términos de totalidad de los derechos fundamentales permite igualmente a FERRAJOLI una reformulación del pacto social como síntesis de los artificios tendentes a garantizar los derechos: se habla así de «pacto de no agresión asegurado por la garantía de los derechos individuales de libertad» y de «pacto de mutua solidaridad asegurado por la garantía de los derechos sociales» (II, p. 569). Sin lugar a dudas, este pasaje también permite observar que corresponde a ROUSSEAU el mérito de haber valorizado la idea del contrato como «metáfora del momento constituyente de la democracia constitucional» y de haber puesto de relieve el problema de «cómo conjugar el principio de la autodeterminación, sobre el que se basa la democracia política, con el carácter heterónomo del derecho positivo» (II, p. 166). Sobre el plano teórico se le reconoce a FERRAJOLI — y no es poco el reconocimiento- el haberlo logrado con claridad. Naturalmente, se debe advertir que a inicios del siglo XXI no consuela haber resuelto el problema de ROUSSEAU sólo teóricamente, sobre todo cuando la solución práctica se perfila hoy en día incluso más lejana, puesto que ya no debe ser buscada a nivel local, sino global. Lo que tenemos en frente, como reconoce nuestro autor, es una obra inactual ${ }^{14}$.

3. La imponente construcción de FERRAJOLI, más allá de la intrincada e impresionante red de bifurcaciones que la atraviesan, está obsesionada por el imperativo de la reductio ad unum. De hecho, toda la máquina analítica está dirigida - y no se puede menospreciar su rigor - a la transformación de todos los problemas políticos en problemas de garantías de los derechos. Con el nacimiento del Estado constitucional de Derecho se ha llevado a cabo, en su opinión, una auténtica revolución copernicana: el

${ }^{14}$ Principia iuris, I, p. 11. Sobre este desfase se ocupa también, con muchas observaciones considerables, E. Vitale, 2008: «Principia iuris. Un'utopia realistica», Critica marxista, I, pp. 59-65 (dicho sea de paso, en el manuscrito originario, como el autor me ha comunicado, el título tenía prudentes signos de interrogación). 
Derecho ya no es concebido como instrumento de la política y la política ha sido elevada a instrumento de la actuación del Derecho (II, p. 44). No obstante, no se puede obviar el aspecto problemático de esta revolución copernicana que consiste en lo que podríamos definir como blindaje jurídico de la democracia. Sin embargo, para el autor, este problema parece no subsistir (para él, evidentemente, aún más que lo fue para KELSEN, se trata de un problema aparente, producto de una falsa conceptualización de la política). BobBIo fue el teórico de las «promesas no cumplidas de la democracia». FERRAJOLI es el teórico de la obligatoriedad del cumplimiento de aquellas promesas. Cumplir con esta obligación no parece ser difícil: basta tomar en serio el Derecho y los derechos. En su teoría, la «esfera de lo indecidible», ya que ha sido preestablecida por un Derecho sobre el que es mejor no indagar a fondo sus orígenes ${ }^{15}$, se expande sin medida (con razón, en mi opinión, A. PINTORE habla de «derechos insaciables»).

En la medida en que se habla de democracia substancial, entendiendo por ésta un sistema de deliberación colectiva donde la sustancia de la decisiones está configurada por límites, establecidos por los derechos individuales de libertad y de autonomía (qué no se debe decidir), así como por los derechos sociales (qué se debe decidir) (II, p. 18), FERRAJOLI esboza los lineamientos de una forma de gobierno en la cual los poderes de gobierno se encuentran tan asediados por las instituciones de garantía que llegan a paralizar su capacidad innovadora (la innovación política es siempre lesión de intereses y transgresión de normas consuetudinarias, y en cuanto tal puede ser interpretada como lesiva de derechos) ${ }^{16}$. Con la contraposición entre instituciones de gobierno (en las que se incluyen tanto el poder legislativo como el ejecutivo) e instituciones de garantía (en las que, junto al poder judicial, se incluyen todos aquellos órganos cuya legitimación proviene únicamente de la sujeción a la ley: lo de FERRAJOLI es un verdadero programa para englobar a la administración en el ámbito de las instituciones de garantía), se acoge la novedad que atañe a la clásica (montesquiniana) separación de poderes públicos, pero sobre todo se invierte la tradicional jerarquía entre ellos, al igual que la relación entre democracia y constitución.

En vez de democracia constitucional, la forma de gobierno esbozada en esta obra merecería llamarse «régimen de constitucionalismo democrático». Las motivaciones de la elección pueden ser halladas en una precisa diagnosis histórica: «en el viejo Estado liberal garante sólo de los derechos civiles y de libertad, el Estado de Derecho tenía una valencia conservadora; mientras la democracia, permitiendo la representación de una mayoría de pobres, tenía más bien una valencia social y también progresista. Hoy sucede lo contrario: el Estado constitucional de Derecho es un defensor de las garantías de los sujetos más débiles contra las tendencias conservadoras de la mayoría; y pre-

${ }^{15}$ «La esfera de lo "indecidible que", es decir, de aquello que no está permitido (o está prohibido) decidir, determinada por el conjunto de los derechos individuales, los cuales impiden, en cuanto expectativas negativas, decisiones que puedan lesionarlos o reducirlos; y, la esfera de lo "indecidible que no", es decir, de aquello que no es permitido no (o es obligatorio) decidir, determinada por el conjunto de derechos sociales, los cuales imponen, en cuanto expectativas positivas, decisiones idóneas dirigidas a satisfacerlas» (II, p. 19).

${ }^{16} \mathrm{Si}$ en un modelo como aquel diseñado por FERRAJOLI la capacidad innovadora de las instituciones de gobierno no resultase paralizada esto sería, según mi punto de vista, solamente indicio de ineficacia, por ejemplo de la recíproca neutralización, de las instituciones de garantía. Observando atentamente las instituciones de gobierno delineadas por FERRAJOLI, éstas recuerdan, si bien en un marco liberal que no excluye el conflicto y la competencia, el escenario marxista donde al dominio de los hombres le ha sustituido la administración de las cosas. 
cisamente la ideología liberal ha descubierto paradójicamente como equivalente político de la libertad del mercado, el valor de la democracia rousseauniana» (II, p. 546). Toda la construcción fundada sobre el dualismo entre instituciones de gobierno e instituciones de garantía sorprende por su asimetría: de las primeras sólo se habla para denunciar las involuciones y las patologías, las segundas sólo se mencionan con propósito constructivo. De nuevo, las razones estructurales de la dinámica expansiva que implican estas últimas son correctamente individualizadas, pero con la proclamación del «principio de la plenitud de las garantías» (II, p. 202) el maximalismo vuelve a apoderarse del autor.

En el ensayo Diritto e guerra (1965), BoBBio escribía: «La función del Derecho puede ser comparada a la presa y a la canalización de una corriente de agua. Un ordenamiento jurídico representa la presa y la canalización de los poderes existentes en el grupo social: del gran dique que permite la formación de la cuenca recolectora - la Constitución - se llega hasta la cotidiana y menuda obra del campesino que abre y cierra los surcos de su campo con un poco de tierra, esto es, metáfora aparte, a las normas particulares que cierran o abren, respecto a éste o a aquel individuo, impidiendo un flujo de poder - normas prohibitivas - o consintiendo la desembocadura de este mismo flujo de poder — normas permisivas- Hasta ahora ningún ordenamiento jurídico ha sido una presa y un canalizador perfecto: algunas veces el agua se pierde en arroyuelos no previstos por el plan de irrigación y va por cuenta propia, son los poderes residuales; otras veces se rompen las presas, o inclusive el gran dique, y es el momento del poder extraordinario» ${ }^{17}$. FERRAJOLI quiere perfeccionar la canalización eliminando del ordenamiento jurídico toda especie de poderes residuales y cada huella de poder extraordinario.

Naturalmente, un programa de controles jurisdiccionales de inconstitucionalidad, no sólo para violaciones de normas, sino también para omisiones de leyes de actuación, está estructuralmente expuesto al riesgo de la improductividad y futilidad. Este control, se advierte en uno de los pasajes donde el hipergarantismo del autor debe plegarse al realismo de la experiencia, «no va más allá de la simple denuncia de la laguna y de la consecuente recomendación de colmarla, en el mejor de los casos fortalecida con la previsión de la obligación de pronunciarse a cargo del legislador, obviamente no sancionable sino en la forma de responsabilidad política. Es claro que la garantía jurisdiccional, en virtud de la separación de poderes, no puede avanzar hasta llegar a usurpar la función legislativa» (II, p. 223). A FERRAJOLI parecieran no preocuparle los riesgos que pueda alimentar un programa de control jurisdiccional tan exigente como el suyo, tales como un conflicto crónico de poderes entre instituciones de gobierno e instituciones de garantía, destinado a ser instrumentalizado por parte de actores políticos estratégicamente orientados y a ser resuelto a favor de las primeras, generando como rechazo la involución hacia una forma de democracia plebiscitaria (y, sin embargo, la lección italiana, también en materia de garantismo penal, a estas alturas, debería ser clara).

Si la democracia constitucional es aquello que FERRAJOLI define, entonces vale para ella el veredicto que ROUSSEAU pronunciaba para la democracia tout court (que en sus p. 110 .

${ }_{17}$ N. BobBio, 1979: «Diritto e guerra», en Il problema della guerra e le vie della pace, Bologna: Il Mulino, 
propósitos, como hemos sugerido, debería haber garantizado el carácter substancial de los derechos humanos): no está hecha para los hombres. Como ideal iluminista de un gobierno fundado sobre la autolimitación de la razón legisladora este modelo en abstracto podría parecer deseable. Sin embargo, resulta del todo implausible considerar que mediante la potenciación de las funciones de garantía sea posible detener la deriva plebiscitaria que se produce en las democracias contemporáneas. Demasiados indicios, escrupulosamente registrados inclusive en esta obra, nos dicen que estamos yendo hacia una universalización del particularismo comunitario, hacia una colonización de los derechos fundamentales a causa de los derechos patrimoniales y, por tanto, hacia una edad de los derechos contratados. En particular, la tetracotomía de los derechos elegantemente elaborada por FERRAJOLI en esta versión última de la corriente filosófica del Derecho constitucional europeo, podría presentarse como una arcaica ejercitación de un epígono del iluminismo jurídico.

4. Lo que llama la atención en la obra de FERRAJOLI es la extrema e insostenible separación entre el realismo de la diagnosis y el radicalismo utópico de la propuesta normativa anclada en la búsqueda de un constitucionalismo no sólo más allá del sino contra el Estado. El diagnóstico concierne, por un lado, a las amenazas a la democracia constitucional en lo que se refiere a la involución plebiscitaria y a la pérdida de representatividad de las instituciones de gobierno, así como a la creciente colonización de la esfera pública a favor de los intereses privados ${ }^{18}$; y por el otro lado, a la ausencia de Derecho público en la arena internacional, caracterizada, respecto a la promesa de un cambio de paradigma en la edad de la globalización, por una «regresión neo-absolutista a la ley del más fuerte sea por parte de los Estados militarmente más potentes, sea por parte los grandes poderes económicos transnacionales» ${ }^{19}$. De este modo, la bobbiana «edad de los derechos» se transforma en las páginas de Principia iuris en la «edad de la máxima desigualdad: entre los ciudadanos y no ciudadanos que presionan nuestras fronteras, pero inclusive, al interno de nuestros países, entre ciudadanos optimo iure, semiciudadanos más o menos establemente regularizados, no ciudadanos y no personas clandestinas» (II, p. 352).

La democracia constitucional de FERRAJOLI persigue no obstante una ardua finalidad, la de conjugarse, en el interior, con la democracia multicultural y, en el exterior, con la democracia cosmopolita. El universalismo de los derechos humanos de su propuesta «no sólo no se opone al multiculturalismo, sino que, al contrario, es el nexo principal del respeto y de la tutela de las diferentes culturas e identidades, inclusive de aquellos que no comparten su valor ni su legitimidad» (II, p. 568). Esta finalidad junto a este universalismo necesitan, para lograr reconocimiento y concreción, de un sistema internacional de garantías. En concreto, se propone una reforma radical de la ONU que remueva los vicios constitutivos, que son principalmente la naturaleza oligárquica del Consejo de Seguridad y su falta de efectividad en la tutela de la paz por falta de actuación de la Carta; y propone, además, objetivos aún más ambiciosos, una Carta interna-

\footnotetext{
18 «Las amenazas más graves a la democracia constitucional provienen hoy de dos potentes ideologías de legitimación del poder: la idea del la omnipotencia de las mayorías políticas y la idea de la libertad de mercado, en tanto nueva Grundnorm del actual orden globalizado» (II, p. 72).

${ }_{19}$ «Al desarrollo de fuerzas y poderes no reglados y de sus agresiones a bienes y a derechos fundamentales corresponden, en vez de una ampliación y de un fortalecimiento de la esfera pública, una reducción en los ordenamientos internos y una casi total carencia en el Derecho internacional» (II, p. 496).
} 
cional de bienes fundamentales y el correspondiente sistema de garantías que debe coincidir con «una esfera pública supranacional en tanto esfera heterónoma respecto al mercado» (II, p. 583).

Pero el modelo de una democracia inclusiva y respetuosa de las diferentes culturas de la sociedad de la globalización permanece innegablemente distante. FERRAJOLI no duda en adoptar, para describir las actuales dinámicas sociales, un lenguaje particularmente crudo: habla de «apartheid interno, que se añade al apartheid mundial efectuado con nuestras fronteras cada vez más inaccesibles», y denuncia con indignación el «nuevo racismo institucional manifestado por políticas y leyes de exclusión, de expulsión y discriminación» (II, pp. 353-54). La fragmentación de la ciudadanía en una pluralidad de status civitatis es un dato de hecho y es indudable que está produciendo situaciones intolerables de desigualdad y discriminación (que requieren respuestas jurídicas, no universalistas sino pragmáticamente particularistas); pero la solución de derribar el obstáculo, exigiendo la cancelación de los privilegios de ciudadanía en una fase de la globalización en la que ya están seriamente corroídos por el mercado, no sólo no es realista sino que pone en peligro los frágiles equilibrios de la democracia constitucional: la realidad es que la predisposición a la inclusión que presenta tal forma de gobierno, históricamente originada por la evolución del Estado nacional cerrado, es muy limitada. Que se deba hablar de racismo y no sólo de xenofobia a propósito de nuestros ordenamientos sociales es desgraciadamente cierto: pero resulta equivocado circunscribirlo al «racismo institucional» sin constatar cómo éste es más bien el reflejo de un racismo social difundido (que no es sólo una construcción de los mass-media y el producto de campañas populistas de alarma social).

El programa de juridificación parece aún más problemático sobre la vertiente del Derecho internacional, donde en la persistente soberanía de los Estados y en el carácter excluyente de las ciudadanías, la perspectiva normativista de FERRAJOLI está obligada a ver sólo «factores de antinomias y de lagunas» (II, p. 494), causa de «inefectividad estructural» de los derechos humanos tan enfáticamente proclamados por las Declaraciones internacionales ${ }^{20}$. En lo que se refiere a sus objetivos, el programa normativo de FERRAJOLI es en el fondo reducible a la racionalización y reformulación en un sistema coherente de cuanto ya pertenece al bagaje del Derecho constitucional e internacional de los tiempos recientes. El art. 28 de la Declaración universal de los derechos humanos de 1948 reza: «Cada individuo tiene derecho a un ordenamiento social e internacional en el cual los derechos y las libertades enunciadas en esta Declaración puedan ser plenamente realizados». Principia iuris es en el fondo la expresión sistemática más explicita de todas las implicaciones de este artículo, tomado en serio.

En relación al diagnóstico, es correcto sostener que en términos generales «el Estado nacional está perdiendo su propia autosuficiencia y exclusividad normativa sobre el plano jurídico, su propia soberanía sobre el plano político, su propio protagonismo sobre el económico» (II, p. 482); mientras que, al mismo tempo, máxima paradoja del

${ }^{20}$ También acá la radicalización del punto de vista de BoBBiO: «El ordenamiento internacional se configura así como un conjunto de lagunas, o sea, de promesas no mantenidas: como un ordenamiento del cual se estipulada la razón social — la paz y los derechos humanos_- pero que se encuentra aún casi enteramente por construir y del cual contamos sólo el bosquejo de la arquitectura» (II, p. 495). 
presente, «la soberanía continúa caracterizando a las relaciones internacionales» (II, p. 492). Lo que obstaculiza la transición hacia un régimen de constitucionalismo cosmopolita, o, como el autor prefiere decir, «cosmopolitismo jurídico policéntrico y pluralista» (II, p. 553), es precisamente el principio de la soberanía externa y el nexo entre ciudadanía y derechos humanos, ambos destinados a entrar en contraposición con la Carta de la ONU y la Declaración universal de los derechos humanos. «Es en esta aporía, aún irresuelta, en la que reside el problema más grave y difícil de la actual teoría del Derecho y de la democracia» (II, p. 493). Las consecuencias están en las desigualdades que proliferan en cada nivel, comenzando por aquellas relativas al status civitatis (antes mencionadas): desigualdades que terminan por agudizar la sensación largamente difundida (sobre la que debería abrirse un largo discurso) de una contracción de las libertades.

Llevando a sus últimas consecuencias la crítica kelseniana al concepto de soberanía, FERRAJOLI se ve obligado, por la lógica misma de su argumentación, a someter la esfera pública internacional a un test de normatividad que no conoce precedentes en la filosofía política. En este ámbito se hace aún más evidente cómo se mueven en contraposición incluso respecto a algunos herederos de la teoría crítica de la sociedad (también respecto a HABERMAS, su punto de vista parece teoréticamente más «conservador» ${ }^{21}$, que en materia de reforma de las organizaciones supranacionales y de recurso a políticas coercitivas dirigidas a evitar catástrofes humanitarias han asumido posiciones más articuladas (aunque también más contradictorias, desde el momento que advierten las contradicciones que se encuentran en la realidad).

El autor de Principia iuris restringe el campo respecto al ámbito de observación de BoBвiO, quien, en el ya citado ensayo de 1965, ilustraba cuatro modos de considerar la relación de la guerra con el Derecho: «la guerra como antítesis del Derecho, como medio para realizar el Derecho, como objeto del Derecho, como fuente del Derecho» ${ }^{22}$. La guerra, para FERRAJOLI, o más precisamente la guerra que ha cambiado su naturaleza en virtud de la revolución tecnológica, emerge sólo como «negación» o «antítesis del Derecho», lo que hace inviable también la concepción de la guerra como sanción y, consecuentemente, toda teoría de la «guerra justa» ${ }^{23}$. Esta afirmación es además el coherente corolario de la reducción de la soberanía a un «principio antijurídico, que sólo designa un vacío de Derecho, siendo su regla la ausencia de reglas, o sea la ley del más fuerte» (II, p. 493) ${ }^{24}$. Aquí FERRAJOLI se nos presenta, a ser posible, aún más hobbesiano que BOBBIO al afirmar la «oposición entre Derecho y guerra, entre garantía del derecho a la vida y violencia no reglada» (II, p. 495).

${ }^{21}$ Sobre el tema, $c f r$. G. NOLTE, 2008: «Das Verfassungsrecht vor den Herausforderungen der Globalisierung», en Veröffentlichung der Vereinigung der Deutschen Staatsrechtslehrer, vol. 67, Berlin: De Gruyter, pp. $129-159$.

${ }_{22}$ «Diritto e guerra», en Il problema della guerra e le vie della pace, cit., pp. 97 y ss.

${ }^{23}$ Principia iuris, II, pp. 501-502. «El derecho internacional cambia así de naturaleza porque cambia la naturaleza de la guerra. Interdictando jurídicamente la guerra, ya que, de todos modos se ha vuelto injustificable moralmente la Carta de la ONU y, en lo que se refiere a Italia, la Constitución república han puesto fin a la cuestión de la justicia o de la injusticia de la guerra — cualquiera esta sea — con la afirmación en todo caso de su ilegalidad».

${ }^{24}$ También en este caso FERRAJOLI lee la historia del Derecho público moderno, adoptando una perspectiva rigurosamente ex parte populi y, por tanto, no como lucha por la afirmación de la soberanía (según la tradicional perspectiva ex parte principis) sino como «lucha contra la soberanía» (II, p. 494). 
5. La insostenible divergencia entre la lucidez del diagnóstico y la ambición del programa normativo compele a la búsqueda de ilusorias vías de salida del laberinto de las antinomias y de las lagunas. El rigor axiomático no excluye así la involuntaria fraudulencia de la argumentación. Constantemente, en el curso de la obra se busca garantizar al lector el realismo del análisis y la gradualidad de las propuestas, afirmando que en la política permanece el espacio de lo decidible. Sin embargo, con la misma perseverancia se trabaja para cerrar cada orificio que pueda permitir la discrecionalidad del actuar político. En las normas constitucionales se querría anclar la erogación de «un salario mínimo garantizado a todos, desde la mayoría de edad, aumentable sólo por el número de hijos menores y quizá integrado, tras cierta edad, en una jubilación» (II, p. 407). Es plausible sostener que garantías de este tipo — «aseguradas en los automatismos del universalismo de los derechos que los hacen posibles»- sean las únicas que resulten efectivas, pero es absurdo afirmar (y es síntoma de un anti-estatalismo perjudicial y de una imagen distorsionada de la burocracia que nos lleva directos al Marx crítico de la filosofía hegeliana del Derecho público) que «aunque muy costosas, son tal vez mucho menos costosas que aquellas consistentes en erogaciones de las mismas prestaciones en forma selectiva y discrecional, con los enormes costos y derroches que genera la gran cantidad de aparatos burocráticos y complejos controles requeridos» (II, p. 408). El sueño de la extinción del Estado continúa persiguiendo la fantasía de una sociedad de individuos hipergarantizados. De un adiestrado crítico del neoliberalismo como FERRAJOLI no se esperaría la adopción de un típico argumento anarco-liberal (si se quiere abolir la corrupción se debe abolir la burocracia). Por otra parte, en un sistema totalmente despenalizado tampoco habría ya más crímenes; y FERRAJOLI, que en Derecho penal no adopta la tesis abolicionista radical, es sin embargo bastante indulgente en relación con una perspectiva de este tipo ${ }^{25}$.

Para asegurar garantías efectivas a los derechos sociales se fomenta «la introducción en las cartas constitucionales de rígidas limitaciones presupuestarias en materia de gasto social, estableciendo para cada derecho social la cuota mínima del presupuesto estatal que debe ser destinada a su garantía» (II, p. 402). FERRAJOLI propone una cuota del 25 por 100 para la educación, igualmente para la sanidad, naturalmente evita mencionar cuota alguna destinada a financiar políticas coercitivas destinadas a la seguridad interna y a la defensa: es transparente su auspicio de que en el cuadro de una política de redistribución tan ambiciosa no quede prácticamente ningún recurso para este tipo de políticas. ¿Piensa nuestro autor derrotar así realmente a las grandes asociaciones de intereses que estructuran las constituciones materiales de los regímenes, inclusive democráticos?, ¿piensa realmente redefinir así las coordinadas de nuestras constituciones económicas?

El problema de la eficacia de las propuestas expuestas y de sus efectos colaterales emerge de modo aún más evidente en relación a la esfera pública internacional, en particular a la ilegitimidad de la guerra y al uso legítimo de la fuerza. El pacifismo jurídico al cual el autor se adhiere «no excluye absolutamente el uso legítimo de la fuerza por parte de una autoridad constituida» a fin de mantener la paz, postulando que entre gue-

25 A estas temáticas, a la cual, como es sabido, había dedicado el fundamental volumen Diritto e ragione. Teoria del garantismo penale (Roma-Bari: Laterza, 1989), vuelve también en Principia iuris: cfr. II. Aquí es nueva la discusión de la reciente teoría del «Derecho penal del enemigo» (G. JAKOBS), II, pp. 537-542 y 634-635. 
rra y uso legítimo de la fuerza existe «una diferencia radical» (II, p. 503); pero precisamente en este punto su argumentación choca con una dificultad insuperable, pues o bien se toma en serio el ejercicio legítimo de la fuerza (dirigido exclusivamente a contrastar violaciones del Derecho internacional), lo que implicaría inevitablemente que las fuerzas armadas en juego terminaran cometiendo crímenes de guerra (las guerras asimétricas en términos tecnológicos que se llevan a cabo contra combatientes que adoptan métodos terroristas terminan fatalmente por implicar a la población civil; análogamente no es posible detener un genocidio perpetrado en el curso de una guerra civil sin cometer crímenes de guerra o hacerse co-responsables de crímenes contra la humanidad); o bien se toman en serio los derechos a la incolumidad de la población civil y se adoptan estrategias de contención militarmente ineficaces y en definitiva perdedoras, capaces solamente de postergar la prueba de fuerza decisiva, consintiendo a quien se sitúa fuera del Derecho la total ejecución de políticas de persecución de minorías y de limpieza étnica. Esto significaría, por un lado, que la diferencia entre guerra y uso legítimo de la fuerza puede ser considerada «radical» bajo el perfil jurídico, pero no lo es y no puede serlo en cuanto a los hechos ${ }^{26} \mathrm{y}$, por otro, que un total sometimiento de la fuerza a las formas del Derecho tiene como efecto su debilitamiento, es decir, su desnaturalización en cuanto fuerza.

Es seguramente legítimo formular dudas sobre la eficacia de la guerra como instrumento para contrarrestar al terrorismo internacional, pero análogas consideraciones escépticas deberían ser expuestas en relación a la eficacia del instrumento jurisdiccional y de una fuerza internacional de policía proveniente de la coordinación de las diversas policías nacionales. «Por otro lado, hubiese sido posible —escribe el autor en relación al 11 de septiembre_-, gracias a la solidaridad generalizada que se manifestó hacia los Estados Unidos, una movilización de las policías y de los servicios secretos de medio mundo, a fin de capturar a los culpables e identificar la red de sus seguidores (...) Seguramente, si hubiesen prevalecido la paciencia y la razón, hoy el terrorismo estaría mucho más aislado y vulnerable» (II, p. 509). Aquí también sorprende la simplicidad programática que parece, optimistamente, eliminar de golpe los obstáculos que hasta ahí el análisis había diagnosticado puntillosamente: sobre la «solidaridad generalizada» y sobre la predisposición a colaborar por parte de las policías y de los servicios secretos del mundo islámico, al menos, hubiese sido oportuno alguna posterior diferenciación; respecto a las modalidades de empleo legítimo de la fuerza, dirigidas a desarmar y capturar terroristas, se supone que un garantista como FERRAJOLI, en ausencia de una fuerza de policía universal legitimada por el consenso de los Estados, no hubiese tardado

26 Bajo el perfil analítico la distinción del autor es a primera vista impecable: «La guerra es por su naturaleza un uso desmesurado e incontrolado de la fuerza, dirigida al aniquilamiento del adversario y destinada inevitablemente, en sus formas actuales, a golpear a las poblaciones civiles. La acción coercitiva mediante el empleo legítimo de la fuerza es, por el contrario, solamente aquella limitada y controlada, estrictamente necesaria, es decir, ya no para vencer, sino únicamente "para mantener o reestablecer la paz y la seguridad internacional". La diferencia entre las dos se manifiesta en dos elementos: la tutela del inocente y la no instrumentación de la coerción a fines e intereses particulares, aseguradas ambas del uso legítimo de la fuerza en lugar de la guerra» (II, p. 504). Sin embargo, en caso del uso legítimo, cualquiera fuere la fuerza «estrictamente necesaria» para el mantenimiento de la paz: ¿quién decide?, ¿los militares de profesión, los jueces o los diplomáticos? ¿Y quién puede, y cómo, garantizar la no instrumentación de la coerción en una arena política marcada por la competencia hegemónica? ¿Y qué sucede en el caso de que se trace un conflicto entre instituciones de garantías e instituciones de gobierno antepuestas para el mantenimiento de la paz? 
en erigir barreras de garantías contra toda modalidad de intervención no sometida al control jurisdiccional (por otra parte, demostrar la ineficacia de la guerra como medio para contrarrestar al terrorismo internacional no equivale a demostrar la eficacia de las medidas policiales).

Ciertamente, para FERRAJOLI la lucha a largo plazo contra el terrorismo debe apoyarse no tanto sobre medidas coercitivas como sobre un programa de redistribución de la riqueza entre las naciones. De este mismo programa nuestro autor igualmente espera respuestas respecto a aquellas emergencias humanitarias que están alimentando la presión migratoria hacia países occidentales ${ }^{27}$. Sin embargo, estas políticas internacionales presentarían costos económicos, sociales y políticos que, aunque reconociendo a FERRAJOLI un tanto de racionalidad pragmática (la que lo lleva a posponer la satisfacción de los derechos sociales pese a su enfática declaración), ninguna coalición de Estados estaría dispuesta a asumir, ni remotamente, en la actualidad. No es difícil pronosticar que si un grupo de políticos temerarios pusieran seriamente en práctica un programa orgánico de reformas, inspirado en los principios directivos de legislación racional expuestos en estos capítulos de Principia iuris, el mundo occidental conocería una rebelión de las dos terceras partes de la sociedad que probablemente haría palidecer hasta la memoria de los fascistas del siglo XX.

6. Hay, en fin, consideraciones de carácter más general que podrían formularse contra las pretensiones universalistas del paradigma jurídico y político propuesto. Del mismo modo en que es perseverante al denunciar las falacias naturalistas de todos los críticos de su programa normativista, FERRAJOLI es incansable al producir argumentaciones teóricas en sostén de la tesis de que su garantismo constitucional de derechos humanos, redefinido en sentido supranacional, es «distante tanto de la idea iusnaturalista de un universalismo por así decir ontológico de los derechos humanos, concebidos como derechos naturales o inherentes a la persona o a la razón humana; como a la idea consensualista e igualmente cognitivista de un universalismo por así decir político y cultural de los mismos derechos, concebidos como derechos defendidos -o que es legítimo pretender que sean defendidos- por su aceptación universal» (II, p. 567). Sin embargo, un modelo legalista tan ambicioso es indistinguible de la tradición occidental y se alimenta necesariamente de los contenidos del iusnaturalismo cristiano del que es parte preponderante; y es lejano al paradigma de Derecho jurisprudencial que domina otras culturas (en el fondo de la teoría del Derecho y de la política del autor se reconoce claramente un esquema iluminista de filosofía de la historia, que reconduce el progreso jurídico a los tres estadios de Derecho jurisprudencial, Estado legislativo y Estado constitucional de Derecho). En la medida en que se sube (o se baja) la escalera del positivismo jurídico, pasando desde una fase en la cual se impone el vigor de las normas a otra en que se impone su validez formal a otra en que se funda su validez material, nos acercamos al iusnaturalismo.

${ }^{27}$ «Si no estamos en condiciones de ofrecer a la aclamada libertad de emigración la garantía negativa solicitada por el art. 13 de la Declaración de 1948 y consistente en la prohibición de impedir el ejercicio; si una semejante garantía, a causa de la enorme cantidad de problemas —económicos, sociales y políticos- que provoca se configura como una especie de utopía, entonces, es necesario y urgente que por lo menos nos empeñemos en políticas sociales de prevención a la inmigración en los países de emigración; en otras palabras, que se implementen en estos países garantías positivas de los derechos sociales a la subsistencia, a la salud y a la educación cuya satisfacción es sobre todo (...) un presupuesto indispensable de su desarrollo económico» (II, p. 355). 
El programa universalista de FERRAJOLI es así doblemente eurocéntrico: por las matrices iusnaturalistas-cristianas de su concepción de los derechos y de los bienes fundamentales (un componente importante de la teoría, sobre el cual aquí no nos hemos detenido) y por la retraducción en términos de iuspositivismo constitucionalista de esta tradición. Igualmente, la firme afirmación de laicismo que connota la obra está completamente inscrita en el recorrido post-cristiano de la secularización. Leyendo el resto de las páginas filosóficamente más audaces, se tiene a veces la sensación de que la navegación se realiza entre SCILLA y CARIBDIS, expuesta por un lado al riesgo de reintroducir en modo forzado una forma de cognitivismo ético sostenida por el «fundamento cognitivo de la jurisdicción y de las demás funciones de garantía» y por el otro al nihilismo de tener que admitir en última instancia «el carácter opinable de la verdad jurídica y probabilístico de la verdad fáctica» (II, p. 217). Pero sobre estas difíciles cuestiones se deberá volver a discutir, con el debido bagaje de argumentaciones (que es exigido por una obra analíticamente tan generosa y por la que debemos sentir gratitud), en otra sede.

(Traducción de Susana Britez D’Ecclesiis) 
